\title{
The Fishing Ground Formation of Sergestid Shrimp (Sergia Lucens) in the Coastal Waters of Southwestern Taiwan
}

Kuo-Tien Lee

Department of Environmental Biology and Fisheries Science, National Taiwan Ocean University, Keelung, Taiwan 202, R.O.C.

Cheng-Hsin Liao

Department of Environmental Biology and Fisheries Science, National Taiwan Ocean University, Keelung, Taiwan 202, R.O.C., chliao@mail.ntou.edu.tw

Wei-Cheng Su

Fisheries Research Institute, Council of Agriculture, Keelung, Taiwan 202, R.O.C.

Sheng-Hsiung Hsieh

Coastal and Offshore Resources Research Center, Fisheries Research Institute, Council of Agriculture, Kaohsiung, Taiwan 806, R.O.C.

Hsueh-Jung Lu Department of Environmental Biology and Fisheries Science, National Taiwan Ocean University, Keelung, Taiwan 202, R.O.C.

Follow this and additional works at: https://jmstt.ntou.edu.tw/journal

Part of the Marine Biology Commons

\section{Recommended Citation}

Lee, Kuo-Tien; Liao, Cheng-Hsin; Su, Wei-Cheng; Hsieh, Sheng-Hsiung; and Lu, Hsueh-Jung (2004) "The Fishing Ground Formation of Sergestid Shrimp (Sergia Lucens) in the Coastal Waters of Southwestern Taiwan," Journal of Marine Science and Technology. Vol. 12: Iss. 4, Article 5.

DOI: 10.51400/2709-6998.2246

Available at: https://jmstt.ntou.edu.tw/journal/vol12/iss4/5

This Research Article is brought to you for free and open access by Journal of Marine Science and Technology. It has been accepted for inclusion in Journal of Marine Science and Technology by an authorized editor of Journal of Marine Science and Technology. 
The Fishing Ground Formation of Sergestid Shrimp (Sergia Lucens) in the Coastal Waters of Southwestern Taiwan

Acknowledgements

We would like to acknowledge the crew members of RV Hai-Fu for their assistance during samplings. This study was financially supported by the Fisheries Agency of the Council of Agriculture, R.O.C. (Project No. 91AS-1.3.2-FA-F1). 


\title{
THE FISHING GROUND FORMATION OF SERGESTID SHRIMP (Sergia lucens) IN THE COASTAL WATERS OF SOUTHWESTERN TAIWAN
}

\author{
Kuo-Tien Lee*, Cheng-Hsin Liao*, Wei-Cheng Su**, \\ Sheng-Hsiung Hsieh***, and Hsueh-Jung Lu*
}

Key words: sergestid shrimp (Sergia lucens), fishing ground, coastal waters of southwestern Taiwan, mixed layer depth.

\begin{abstract}
The aggregation mechanism of sergestid shrimp (Sergia lucens) in the coastal waters of southwestern Taiwan was studies based on the eleven monthly cruises data including temperature, salinity, nutrients, phytoplankton and zooplankton, collected by research vessel Hai-Fu from August 1999 to June 2000. Mean while, the CPUE (kg/hour) of the shrimp were also estimated from 16 selected sampling vessels. The results indicated that the shrimp aggregates near two major fishing grounds Kaoping River estuary and Fangliao canyon in the coastal waters of southwestern Taiwan at the depth stratum from 100 to $200 \mathrm{~m}$, water temperature in the range of $15-22^{\circ} \mathrm{C}$ and salinity at 34 . 3 34.7 psu, which are named by local fishermen as Kangkou and Sanlunwei fishing grounds, respectively. The formation of fishing ground was related to the mixed layer depth (MLD) as indicated by the monthly variation of environmental factors and daily CPUE which coincided with the peak season of nutrients and phytoplankton and zooplankton. The Kangkou fishing ground was formed at the coastal front mixed by the coastal water and South China Sea surface water during spring and summer, whereas Sanlunwei fishing ground was formed at the upwelling area, which was driven by strong prevailing offshore wind during autumn and winter.
\end{abstract}

\section{INTRODUCTION}

Sergestid shrimp (Sergia lucens, Hansen, 1922) is a diel migration and small meso-pelagic shrimp (Chou et al., 1999). It is characterized by the 161 reddish light

Paper Submitted 05/28/04, Accepted 09/08/04. Author for Correspondence: Cheng-Hsin Liao. E-mail: chliao@mail.ntou.edu.tw.

*Department of Environmental Biology and Fisheries Science, National Taiwan Ocean University, Keelung, Taiwan 202, R.O.C.

**Fisheries Research Institute, Council of Agriculture, Keelung, Taiwan 202, R.O.C.

***Coastal and Offshore Resources Research Center, Fisheries Research Institute, Council of Agriculture, Kaohsiung, Taiwan 806, R.O.C. organs on the body (Omori, 1969), which look like cherry blossoms, and thus called "Sakura Shrimp" in Japan and in Taiwan as well. The shrimp is delicious and directly consumed in fresh by human being.

Omori $(1969,1989)$ indicated that sergestid shrimp aggregated in steep continental shelf canyons, and in area where comes a great influx of river discharge, such as the Suruga Bay, Sagami Bay and Tokyo Bay of Japan (Fig. 1a). And, the sergestid shrimp could also be found in the coastal waters of SW and E Taiwan, and Gueishan Islet in the NE Taiwan (Fig. 1a) (Omori et al., 1988; Omori, 1989; Lee et al., 1996). Due to the coastal waters of SW Taiwan is similar to that of Suruga, Sagami and Tokyo Bays (Chen and Su, 1993) in that they are made up of continental shelf canyons and also receives influx of fresh water from nearby rivers (Fig. 1b). Therefore, the sergestid shrimp was abundantly in the coastal waters of SW Taiwan as commercial fishing was initiated in the SW Taiwan since 1980.

Typical fishing gear used in this region is midwater trawlers and the fishing season begins in early November and ends in late May of the following year. The major fishing grounds of sergestid shrimp in the SW Taiwan were found to be highly aggregated near Kaoping and Fangliao canyon in the depth from 100 to $200 \mathrm{~m}$, which are named by local fishermen as Kangkou and Sanlunwei fishing grounds, respectively (Chen et al., 1998). The fishing vessels increased to 120 in 1999 and operating from morning to evening in these fishing grounds. The average annual catch was approximately 136 to 2,000 tons during the years from 1985 to 2000 (Fig. 2) (Chen, 1999). Although a new self-regulation in restriction of catch capacity was established in 1993, the annual catch still fluctuates greatly.

The resource and ecological distributions of small zooplanktons with fast growth rates, short life spans and 
weak mobility such as the sergestid shrimp are closely related to the variations of the marine environment (Uda, 1972; Kawasaki and Omori, 1986). The fishing ground of the shrimp in the SW Taiwan is situated in the shallow Taiwan Strait and South China Basin, where exhibit complex topographical features (Fig. 1b). In addition, the fishing ground was mixed with Mainland China coastal current (low temperature and low salinity), and Kuroshio branch current (high temperature and high salinity), as well as South China Sea surface water (high temperature and low salinity) (Fan, 1982; Wang, 1986; Wang and Chern, 1989; Chen et al., 1998; Chiou et al., 2000). Furthermore, the influx of water discharge from the Kaoping, Tunkang, Linpien, Shuaimang, Fangshan and Fengkang rivers with the monsoons and seasonal rains (Fig. 1b), results a complicated marine
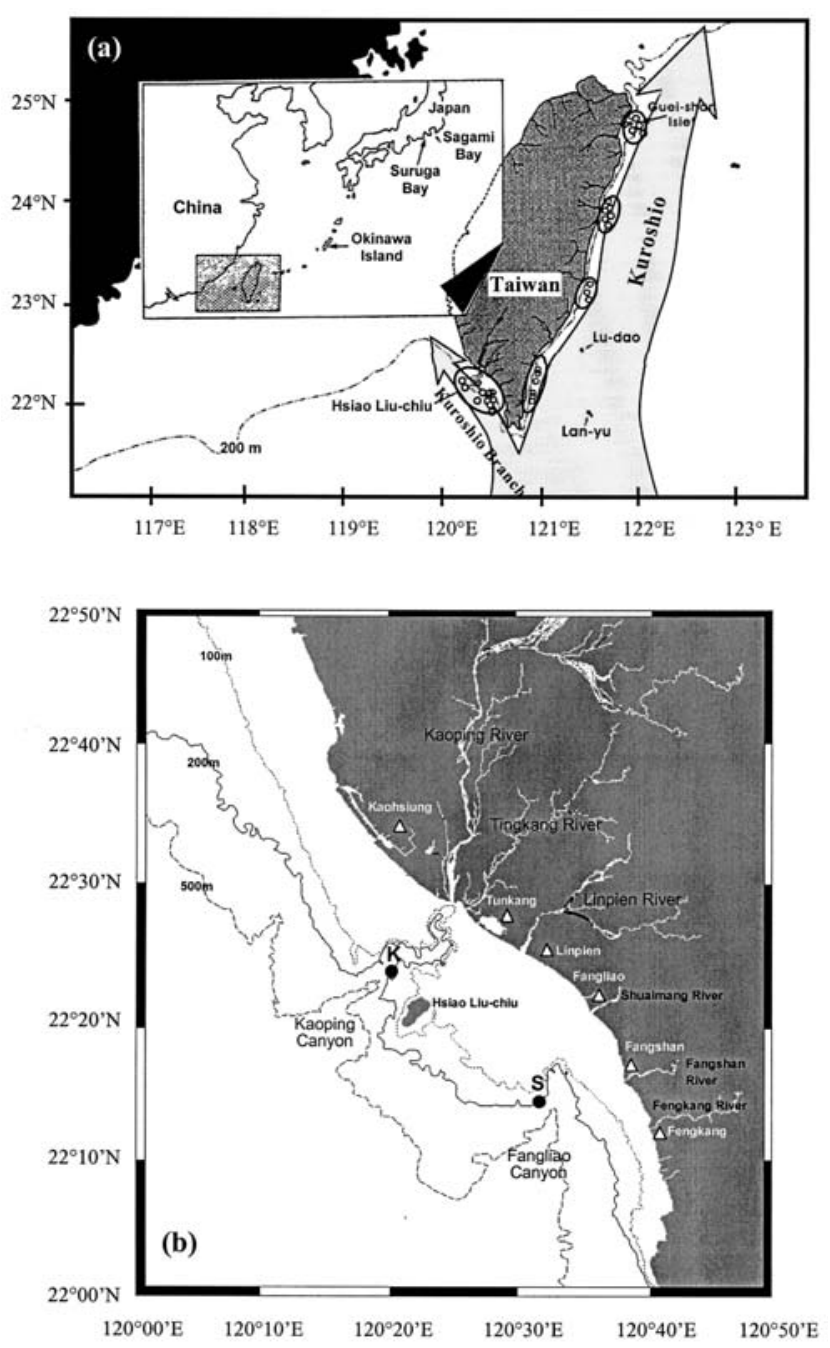

Fig. 1. (a) Sergestid shrimp (Sergia lucens) distributions in the waters along Taiwan's east coast, and in the southwest waters (Lee $e t$ al., 1996). (b) Topography in the waters off Southwestern Taiwan. Black circles indicate the sampling stations $K$ and $S$ for environment factors. environment in this region.

Therefore, the catch of sergestid shrimp in the SW Taiwan was influenced by environmental factors more than fishing effort. The present study focuses on effect of environmental factors on the aggregation mechanism of the sergestid shrimp in the SW Taiwan.

\section{MATERIALS AND METHODS}

\section{Experimental design}

A total of 11 cruises were conducted to investigate the environmental factors by using the research vessel Hai-Fu in the coastal waters of southwestern Taiwan, from August 1999 to June 2000. Sampling stations $K$ (position about in $22^{\circ} 23^{\prime} \mathrm{N}, 120^{\circ} 20^{\prime} \mathrm{E}$ ) and $S$ (position about in $22^{\circ} 15^{\prime} \mathrm{N}, 120^{\circ} 31^{\prime} \mathrm{E}$ ) were set in each monthly cruise (Fig. 1b), due to the commercial fishing of sergestid shrimp in the SW Taiwan aggregated mainly within the Kaoping canyon (Kangkou fishing grounds) and Fangliao canyon (Sanlunwei fishing grounds), with fishing barycenter coordinates located near stations $K$ and $S$, respectively.

Vertical observations of water temperature $\left({ }^{\circ} \mathrm{C}\right)$ and salinity (psu) data were measured with SEB19-01 CTD system. At the same time, GoFlo sampling bottles attached to the Rosette water sampler were used to collect water samples at depth in $5 \mathrm{~m}, 25 \mathrm{~m}, 50 \mathrm{~m}, 75 \mathrm{~m}$, $100 \mathrm{~m}, 150 \mathrm{~m}, 200 \mathrm{~m}$, and $300 \mathrm{~m}$. The water samples collected from these depths were then taken back to the laboratory for nutrients determination (including nitrate, phosphate, silicate and ammonia) and phytoplankton cell counts. Concurrent with the CTD observation, a zooplankton sampler net (Codend mesh size: $333 \mu \mathrm{m}$ ) were used to collect zooplankton from $300 \mathrm{~m}$ to surface. The volume of water filtered through the sampler was calculated by a flowmeter. The net was towed obliquely at a speed of 1-2 knots. The towing depth was monitor-

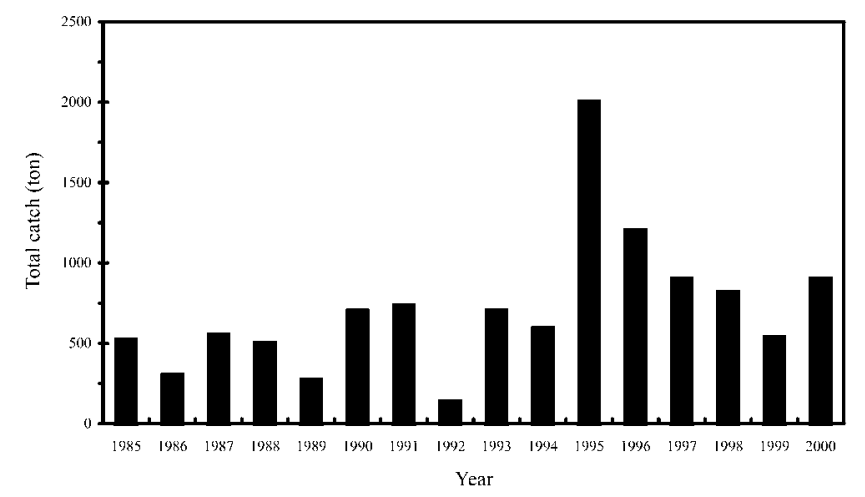

Fig. 2. Annual catches of sergestid shrimp in the coastal waters of southwestern Taiwan, from 1985 to 2000 (Chen, 1999). 
ing by a Scanmar depth sensor (Model 400-Trawl). The specimens collected were preserved in a $5 \%$ formalin solution. For each sample wet weight was measured and the number of individual organisms (including copepoda, chaetognatha, docapoda, appendicularia, medusae, pteropoda, ostracoda, thaliacea, amphipoda, heteropoda, larvae fish, ... and so on) were counted in the laboratory.

\section{Catch data}

Annual and monthly catch data in terms of tons of sergestid shrimp were compiled from the daily landing at the Tun-Kang Fishery Market during 1985 to 2000 fishing seasons.

In situ catch data of the shrimp were collected from 16 mid-water sampling trawlers between August 1999 and June 2000. The data included fishing positions, fishing depth, trawling times, and catch amount.

Due to the limited area available for sergestid shrimp fishing in the SW Taiwan, set regulations are established to minimize interferences among the trawlers. Regulations require that each vessel queuing up one behind the other, and trawl at the same speed from north to south. Each vessel is equipped with nets made by the same manufacturer with similar specifications. This results in each vessel trawling approximately the same sweeping area of net mouth. Therefore, the fishing effort was standardized for hourly intervals in this study, and the catch per unit effort [CPUE $(\mathrm{kg} /$ hour)] was calculated as followed:

$$
\text { CPUE }=\sum_{i=1}^{n} Y_{i} / \sum_{i=1}^{n} T_{i}
$$

where $n$ is the number of sampling vessels in a day, $Y_{i}$ is the catch amount per day by the sampling vessels $(\mathrm{Kg})$, and $T_{i}$ is the daily fishing effort of the sampling vessels, otherwise known as trawling time (hour). The value of CPUE will be an index for population density of sergestid shrimp in each fishing ground.

\section{Data analysis}

The environmental factors including sea surface temperature $\left({ }^{\circ} \mathrm{C}\right)$, vertical water temperature $\left({ }^{\circ} \mathrm{C}\right)$ and salinity (psu), nutrients $(\mu$-atom/L), numbers of individual zooplankton (inds. $/ \mathrm{m}^{3}$ ) and the wet weight of phytoplankton $(\mu \mathrm{g} / \mathrm{L})$, were all collected from stations $K$ and $S$. In addition, the mixed layer depth (MLD) (m), temperature decreases gradually below the thermocline, was computed from the vertical water temperature. The MLD was defined for the depth of temperature lower than $1^{\circ} \mathrm{C}$ to the sea surface temperature. The upwelling or the front of different water masses mixed with river discharge may influence the depth of thermocline (Lalli and Parsons, 1993; Douglas, 1997). The depth of this phenomenon was defined as potential MLD (m). These environmental factors were correlated to CPUE of the two fishing grounds to understand the fishing ground formation mechanisms of sergestid shrimp in the SW Taiwan.

Furthermore, the monthly frequency of winter/ northeast monsoons were computed base on the meteorological data of daily wind direction and velocity which collected from Kaohsiung and Fengkang Branch of the Taiwan Central Weather Bureau in the vicinity of the major fishing ground during November 1999 to June 2000. The monthly average discharges of the Kaoping River were also estimated from the annual report of the Water Resources Agency, Ministry of Economic Affairs, Taiwan, during 1991 to 1999.

\section{RESULTS}

\section{Kangkou fishing ground formation mechanism}

The monthly variations of the relationship between vertical water temperature and salinity at the depth shallower than $300 \mathrm{~m}$ in station $K$, and overlaid with the daily trawling depth and CPUE of the shrimp in Kangkou fishing ground, from August 1999 to June 2000 indicated that the fishing ground distributed mainly at depths from 50 to $200 \mathrm{~m}$, with water temperature 15$25^{\circ} \mathrm{C}$, and salinity 34.2-34.5 psu (Fig. 3).

Based on the data of environment factors from station $K$ indicated that the SST dropped in the early September in the Kangkou fishing ground results in vertical convection (Fig. 4a, b). Once the vertical convection increases due to the drop SST it will facilitate the increase of MLD depth (Fig. 4c). When the SST in the Kangkou fishing ground drops to the lowest, i.e. from 23 to $25^{\circ} \mathrm{C}$, during December and January (winter time), the MLD reaches the maximum depth around 50$60 \mathrm{~m}$ in the same time. However, the SST begins to increase in March, and until May to August (spring/ summer time) it will reach above $28^{\circ} \mathrm{C}$. Then, the vertical convection will induce the MLD to become shallower or insignificant in spring/summer time. In addition, the vertical profile of temperature in Fig. $4 \mathrm{~b}$ shows that the MLD in Kangkou fishing ground not only becomes shallower but also nearly disappeared to the point of generating a potential MLD in August 1999 and June 2000.

The nutrient content of the Kangkou fishing ground begins to increase in September as the MLD increases (Fig. 4d). Between October and February of the following year, the nutrient content remains at the level of 28.35-29.82 $\mu$-atom/L. Beginning in March, however, the nutrient content decreases as MLD decreases, reaches 
less than $10 \mu$-atom/L in April and May. It is not until June, at the formation of potential MLD, that the nutrient content begins to rise again. In turn, this results in an increase in nutrients at the euphotic zone in Kangkou fishing ground. During the same period of time, there is an increase in the growth of phytoplankton (Fig. 4e). At the blooming stage in September and April, nutrients were subsequently depleted. Although zooplanktons do not exhibit a significant blooming as phytoplanktons do, the fluctuation in their density delayed by phytoplankton (Fig. 4f). In the meantime, the variation in CPUE of the shrimp delayed by the fluctuation in density of the zooplankton (Fig. 4g). As Fig. 4g indicates, the most productive fishing seasons can be divided into two periods, one in the winter months of November and December, the other in the spring months of April and May, with the spring season having a higher CPUE.

\section{Sanlunwei fishing ground formation mechanism}

Fig. 5 indicates that the main fishing depth at Sanlunwei fishing ground distributed in the water depths between 100 and $250 \mathrm{~m}$, with water temperatures in the
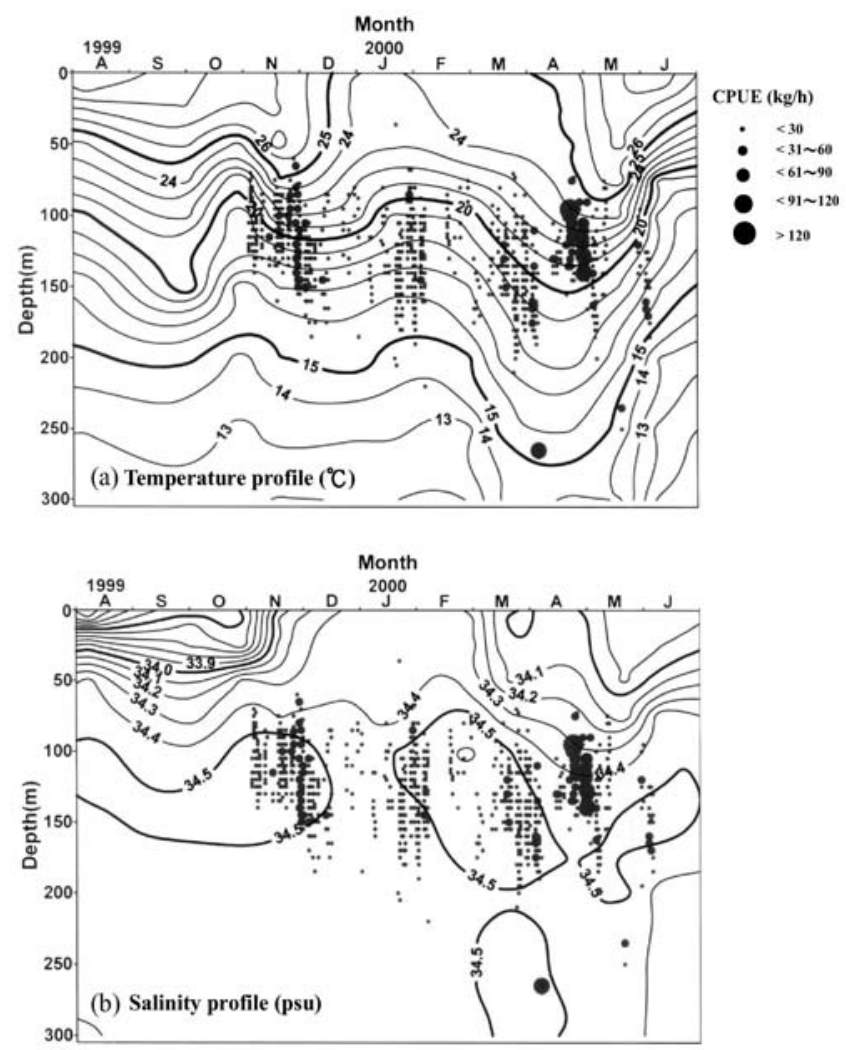

Fig. 3. Monthly variations of vertical water (a) temperature and (b) salinity at depth shallower than $\mathbf{3 0 0}$ meters in the Kangkou fishing ground at sampling station $K$, from August 1999 to June 2000. Different sizes of black circles indicate the daily trawling depth and CPUE of sergestid shrimp from sampling vessels. range of $13-24^{\circ} \mathrm{C}$, and salinity at $34.4-34.7$ psu.

Monthly variations of environment factors at Sanlunwei fishing ground are similar to those of the Kangkou fishing ground (Fig. 6). The MLD in this fishing ground, however, significantly deepens in September (Fig. 6c), becomes slightly shallower in October, but deepens again in November. By January and February, its MLD reaches the maximum depth of 75 to $85 \mathrm{~m}$. The MLD at the Sanlunwei fishing ground (Fig. $6 c$ ) is approximately 15 to $20 \mathrm{~m}$ deeper than that at the Kangkou fishing ground (Fig. 4c).

Although nutrients in the Sanlunwei fishing ground increase with the increase of MLD, they fluctuate drastically in winter (Fig. 6d). In November, for example,
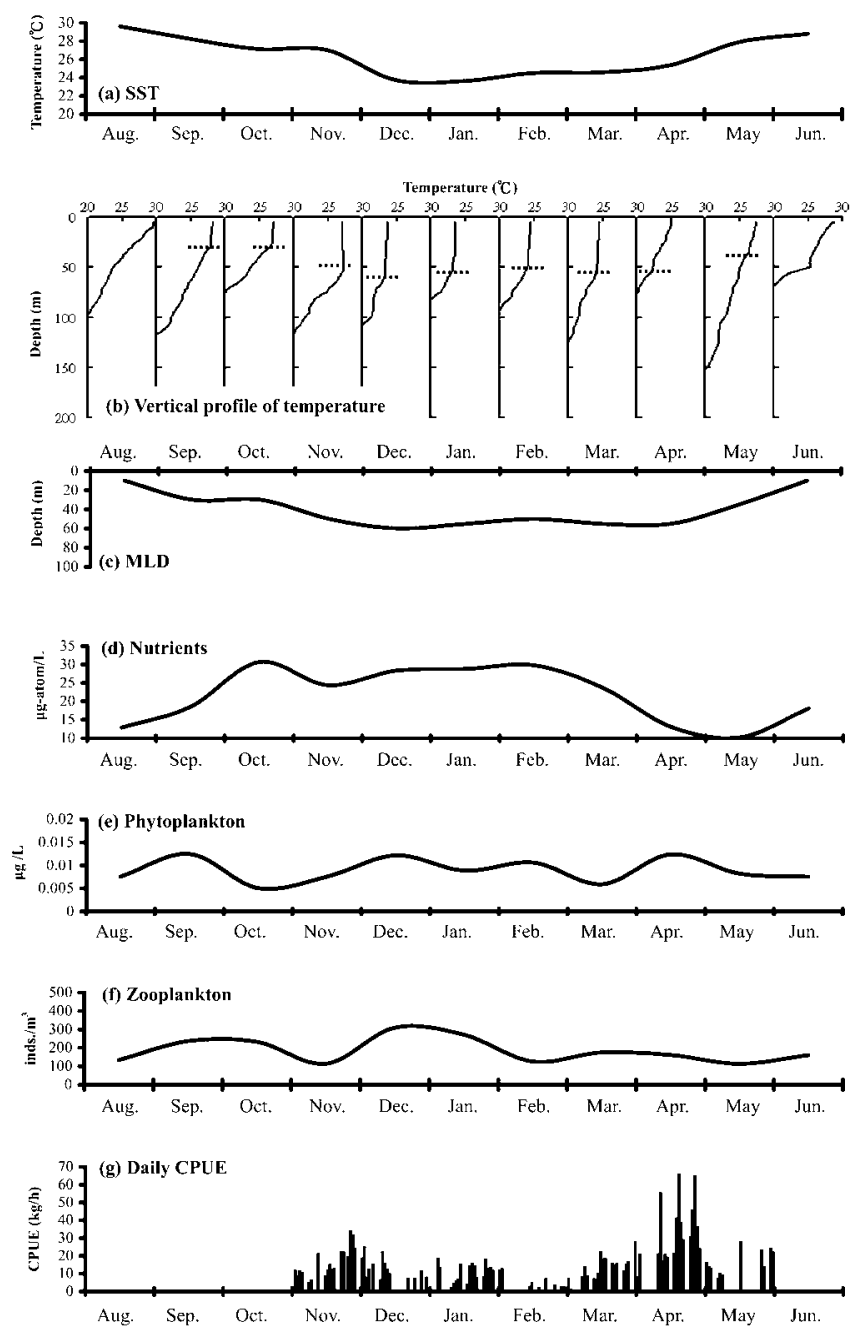

Fig. 4. Monthly variations of (a) sea surface temperature, (b) vertical profile of temperature, (c) mixed layer depth, (d) nutrients content, (e) wet weight of phytoplankton, (f) numbers of individual zooplankton, which observed from station $K$ sampling data, and (g) daily variations of CPUE of sergestid shrimp from sampling vessels in Kangkou fishing ground, from August 1999 to June 2000. 
nutrient content decreases dramatically, but increases to $29.72 \mu$-atom/L in December. In January, it starts to decrease again and reaches a low of $15 \mu$-atom/L or less from March to May. From June forward, the nutrient content increases again.

As indicated in Fig. 4f and Fig. 6f, numbers of zooplankton were greater in Kangkou than in Sanlunwei fishing ground, whereas wet weight of phytoplankton were greater in Sanlunwei than in Kangkou fishing ground (Fig. 4e and Fig. 6e). The timing of phytoplankton bloom was different between Kangkou and Sanlunwei fishing grounds. The blooming period of phytoplankton occurs around December in the Sanlunwei fishing ground, while in April in the Kangkou fishing ground.

The variation of CPUE in the Sanlunwei fishing ground (Fig. 6g) and the Kangkou fishing ground (Fig. $4 \mathrm{~g}$ ) demonstrated that the daily CPUE was higher in Sanlunwei than Kangkou in the winter, but not in the spring.

\section{DISCUSSION}

The formation of the Kangkou and Sanlunwei
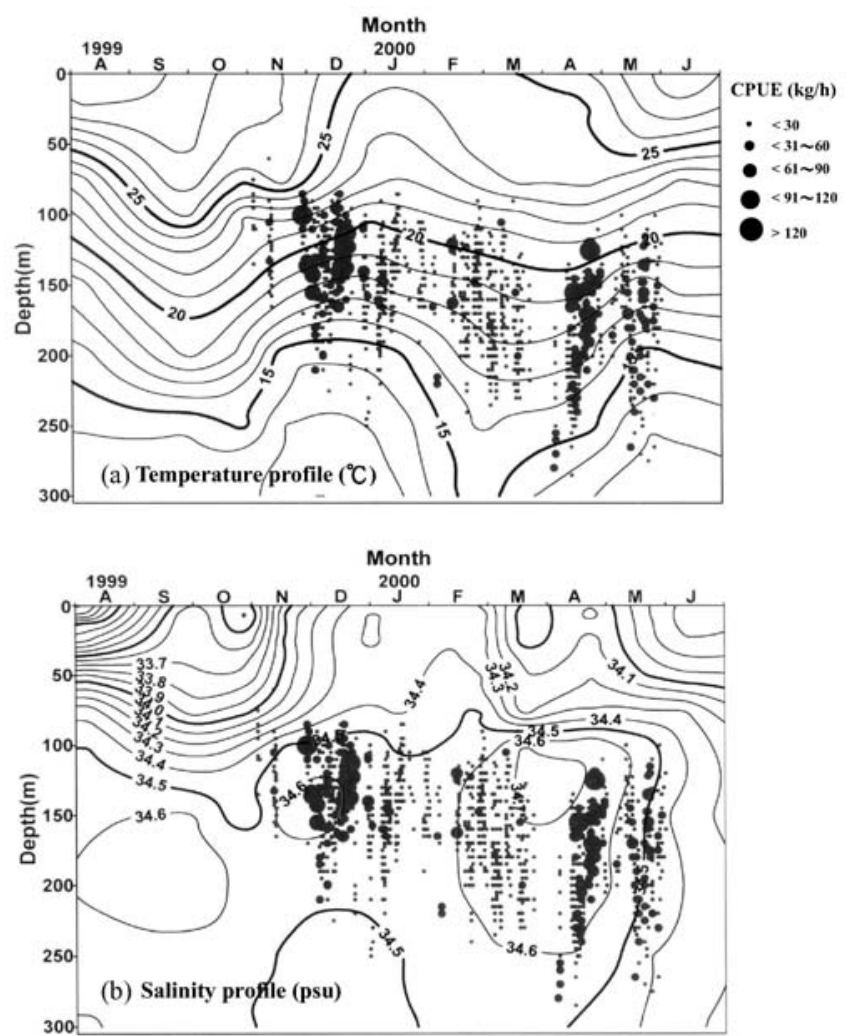

Fig. 5. Monthly variations of vertical water (a) temperature and (b) salinity at depth shallower than $\mathbf{3 0 0}$ meters in the Sanlunwei fishing ground at sampling station $S$, from August 1999 to June 2000. Different sizes of black circles indicate the daily trawling depth and CPUE of sergestid shrimp from sampling vessels. fishing grounds were influenced by the biotic (phytoplankton and zooplankton abundance) and abiotic (temperature, salinity, water masses, changes in MLD and potential MLD, and nutrients) factors. The formation mechanisms of these two fishing grounds were, however, differed greatly in many ways, including the variation in MLD, depletion of nutrients, phytoplankton and zooplankton abundance, and CPUE. These differences depended on climatic changes of the region. For example, the MLD was deeper approximately 15-20 m during autumn and winter (Fig. 4c and Fig. 6c) in Sanlunwei than that in Kangkou fishing grounds. This might be due to winter monsoon effect (Rothchild and Dsborn, 1988). The frequency and wind velocity of the winter monsoon was higher in Sanlunwei
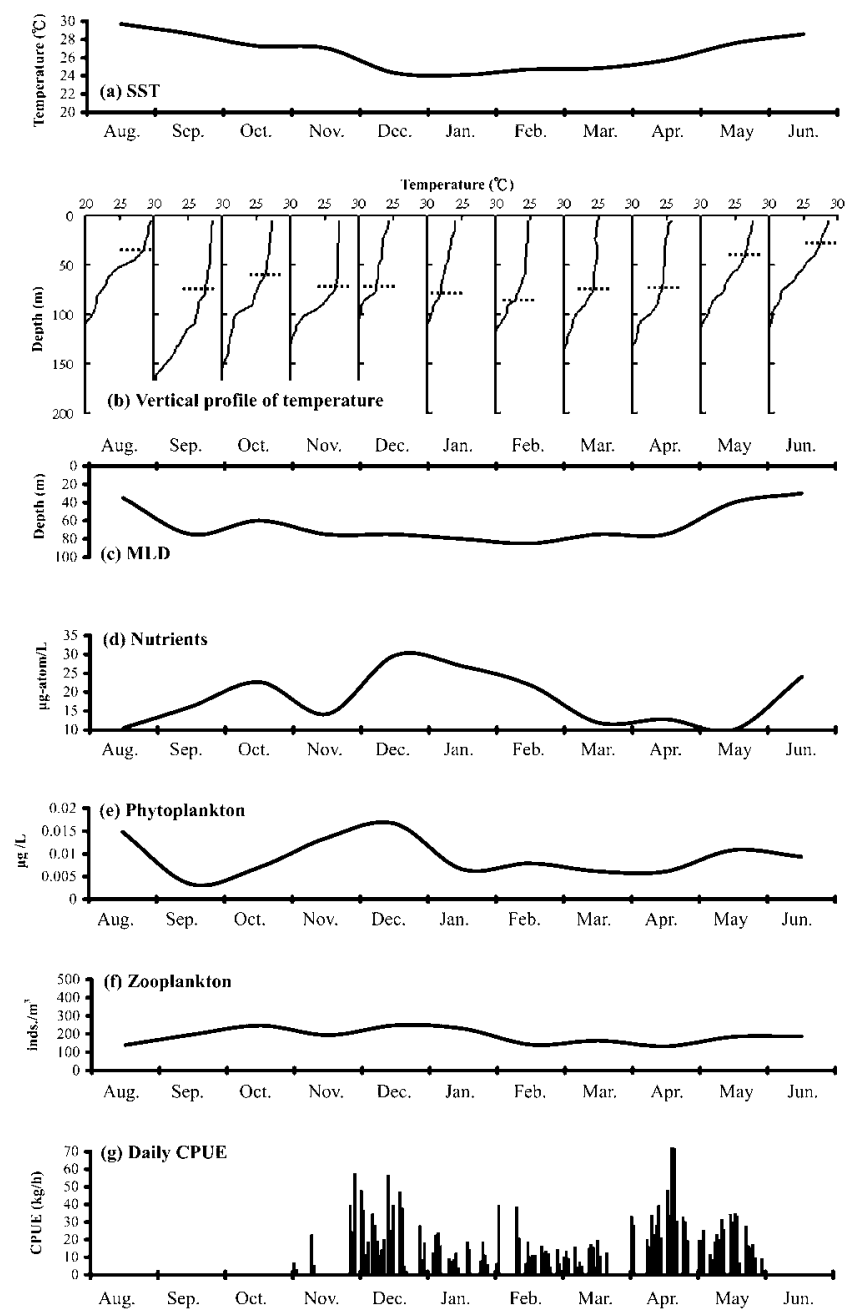

Fig. 6. Monthly variations of (a) sea surface temperature, (b) vertical profile of temperature, (c) mixed layer depth, (d) nutrients content, (e) wet weight of phytoplankton, (f) numbers of individual zooplankton, which observed from station $S$ sampling data, and (g) daily variations of CPUE of sergestid shrimp from sampling vessels in Sanlunwei fishing ground, from August 1999 to June 2000. 
Table 1. Frequency and wind velocity of winter monsoons in Kaohsiung area (nearby Kangkou fishing ground), from November 1999 to June 2000

\begin{tabular}{l|cccccccc}
\hline & Month & Nov./1999 & Dec./1999 & Jan./2000 & Feb./2000 & Mar./2000 & Apr./2000 & May/2000 Jun./2000 \\
\hline Item & 70 & 87 & 84 & 79 & 52 & 23 & 13 & 13 \\
Frequency (\%) & 3.2 & 4.4 & 3.3 & 3.1 & 3.3 & 2.8 & 2.3 & 1.8 \\
Max. wind velocity (m/s) & 1.3 & 1.4 & 1.2 & 1.5 & 1.6 & 1.8 & 1.2 & 1.1 \\
Min. wind velocity (m/s) & & & & & & & & \\
\hline
\end{tabular}

Table 2. Frequency and wind velocity of winter monsoons in Fengkang area (nearby Sanlunwei fishing ground), from November 1999 to June 2000

\begin{tabular}{l|cccccccc}
\hline \multicolumn{1}{c|}{ Month } & Nov./1999 & Dec./1999 & Jan./2000 & Feb./2000 & Mar./2000 & Apr./2000 & May/2000 Jun./2000 \\
\hline Frequency (\%) & 100 & 100 & 90 & 76 & 77 & 47 & 61 & 3 \\
Max. wind velocity (m/s) & 10.6 & 10.6 & 9.9 & 8.4 & 7.8 & 6.4 & 7.0 & 3.5 \\
Min. wind velocity (m/s) & 1.5 & 1.6 & 1.6 & 2.1 & 1.9 & 1.6 & 1.8 & - \\
\hline
\end{tabular}

than in Kangkou fishing grounds (Table 1 and Table 2). Both fishing grounds displayed a below-standard level of nutrients in November (Fig. 4d and Fig. 6d). This phenomenon indicates that nutrients were consumed by the phytoplankton. This depletion of nutrients was especially apparent in the Sanlunwei fishing ground. Further studies of existing phytoplankton in these two regions showed that phytoplankton in the Sanlunwei fishing ground were in their blooming stage. As Lalli and Parsons (1993) indicated, nutrients were not only one of the major energy sources necessary for metabolism in phytoplankton, they were also vital in phytoplankton's proliferation. Therefore, the depletion of nutrients in November in the Sanlunwei fishing ground was a result of consumption by phytoplankton during their blooming stage.

In order to explain why phytoplankton blooming existed more apparent in Sanlunwei than in Kangkou fishing grounds, further examination of the monthly vertical water temperature and salinity in the two regions (Fig. 3 and Fig. 5) showed that during the autumn/ winter months there was an apparent upwelling of sea water in the middle layer at the Sanlunwei fishing ground. Hung et al. (1986) indicated that the upwelling phenomenon in Taiwan's southwestern waters was affected by monsoons and the topography of that region. Lee (1991) also pointed out that offshore winds in this region are formed as a result of northeast monsoons. Moreover, Siegel et al. (1999) stated that nutrients in the middle layer water would be transported to the sea surface if upwelling and mixture of water masses occurred as a result of monsoon in the coastal waters. While nutrients brought forth by such upwelling would facilitate phytoplankton blooming.

Table 1 and Table 2 indicated that the monsoons in Sanlunwei were more frequent and had higher wind velocity than that in Kangkou fishing grounds. Under the strong winter monsoon, offshore winds were formed at the Sanlunwei fishing ground. These offshore winds result in the formation of upwelling, which in turn forms the potential MLD phenomenon (Fig. 6b). Potential MLD replenished the lost nutrient supply and subsequently facilitates phytoplankton blooming. This blooming made high quality sergestid shrimp catch possible, thus the daily CPUE was better in Sanlunwei (Fig. 6g) than in Kangkou fishing grounds (Fig. 4g) during wintertime.

The sea surface temperature in both fishing grounds gradually increased as their vertical convection weakens (Fig. 4b and Fig. 6b) during spring/summer time (March to May). Then, MLD became shallower (Fig. 4c and Fig. 6c), and the nutrients were below standards (Fig. 4d and Fig. 6d).

Fluctuations of monthly existing phytoplankton wet weights in the two fishing grounds (Fig. 4e and Fig. 6e) indicated that in the Kangkou fishing ground, blooms took place in April. According to Siegel et al. (1999), nutrients produced from river discharge along the coasts were another factor affecting the distribution of phytoplankton in coastal waters and facilitates blooming. Fan (1982), Lee et al. (1990) and Lee et al. (1994) also described that during the spring/summer season, southwestern monsoons carrying high temperature and high salinity from surface water of the South China Sea mixed with river discharge along the coasts form a mixed layer water mass of high temperature and low 
salinity, resulting in a significant temperature and salinity waterfront.

The fluctuation profiles of the monthly vertical water temperature and salinity in the Kangkou and Sanlunwei fishing grounds (Fig. 3 and Fig. 5) showed that the vertical gradient structure in the surface layer exhibited a distinct waterfront in spring/summer time, and the waterfront in Kangkou fishing ground was more significant than that in Sanlunwei fishing ground. Data from the Water Resources Agency, Ministry of Economic Affairs, showed (Fig. 7) that during the spring/ summer months, the Kouping River (its estuary near the Kangkou fishing ground), the largest river in southern Taiwan, was at its highest runoff rate. The area of flow that Kaoping River covered and the amount of flow are greater than all rivers together from the Sanlunwei areas. The influx of fresh water from the Kaoping River into the Kangkou fishing ground resulted in the formation of a water boundary front (Fig. 3) and a potential MLD (Fig. 4b). Such influx of fresh water also brought forth nutrients and facilitates phytoplankton blooming in the Kangkou fishing ground (Fig. 4e). The blooming in turn attracted sergestid shrimp to the area thus resulted in high yield during the spring/summer time. It could be found from that nutrient depleted during blooms (Fig. 4d). As for the Sanlunwei fishing ground, spring/ summer months were a period of weak vertical convection and low influx of fresh water, nutrients in the region were therefore not being replenished. Thus the time and rate it takes for nutrients to deplete was far more apparent than that in the Kangkou fishing ground (Fig. 6d).

\section{CONCLUSION}

The present study demonstrated the formation mechanism of sergestid shrimp fishing grounds in the coastal waters of SW Taiwan. The two fishing grounds were not only different in their vertical convection in the winter but also Kangkou received water from Kaoping River in spring and form a boundary front with water

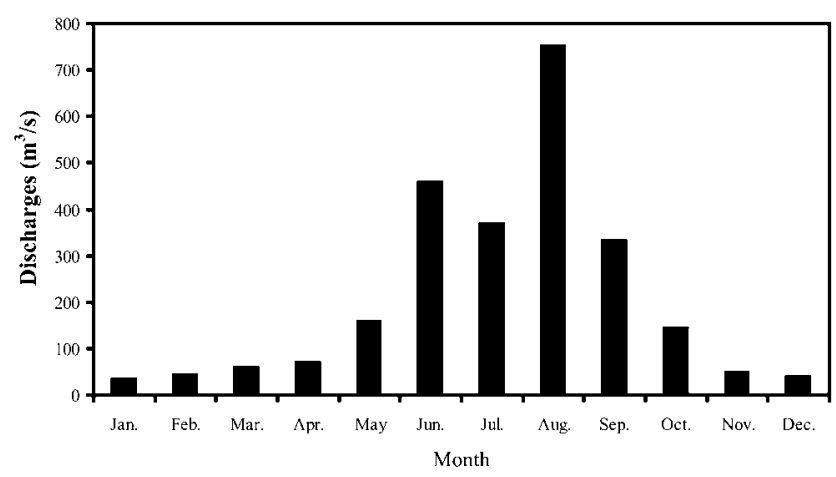

Fig. 7. Monthly average discharges of the Kaoping River. [15] from the South China Sea. The formation of MLD in Kangkou also provided abundant nutrients that facilitate phytoplankton blooming and zooplankton growth. The high amount of food supply in turn attracted sergestid shrimp, thus giving the Kangkou fishing ground a high yields of sergestid shrimp catch.

In contrast, Sanlunwei fishing ground was affected by northeast monsoons in the winter. Such monsoons brought forth offshore winds that result in upwelling. The upwelling in this region provided rich nutrients that ensure phytoplankton blooming and zooplankton growth in the winter. The rich source of food made the Sanlunwei fishing ground an ideal habitat for sergestid shrimp, thus giving the region a high quantity yields of sergestid shrimp catch in the winter.

Due to the lack of comprehensive long-term data on catch and marine ecology of the region, future research on the relationship between fluctuation of sergestid shrimp stocks and ecological variations were recommended, and also the effects of seasonal changes upon the sergestid shrimp groupings, body weight, body length, sexual ratio, and reproduction were important topics that need to be addressed.

\section{ACKNOWLEDGEMENTS}

We would like to acknowledge the crew members of RV Hai-Fu for their assistance during samplings. This study was financially supported by the Fisheries Agency of the Council of Agriculture, R.O.C. (Project No. 91AS-1.3.2-FA-F1).

\section{REFERENCES}

1. Chen, S.R., "Studies on the Fisheries Management of Sergestid Shrimp (Sergia lucens) in Taiwan," Ph.D. Dissertation, Department of Fisheries Science, National Taiwan Ocean University, Keelung, Taiwan (1999). (in Chinese)

2. Chen, S.R. and Su, W.C., "Study on Fishing Efficiency of the Sakura Shrimp Fishery in the Coastal Waters off Southwestern Taiwan," J. Taiwan Fish. Res., Vol. 1, pp. 11-18 (1993).

3. Chen, S.R., Su, W.C., Ho, C.H., and Chow, Y.S., "SpatioTemporal Variation of the Catch Sergestid Shrimp, Sergia lucens Hansen, in the Coastal Waters of Southwestern Taiwan," J. Fish. Soc. Taiwan, Vol. 25, pp. 4556 (1998).

4. Chiou, W.D., Wu, C.C., and Cheng, L.Z., "SpatioTemporal Distribution of Sergestid Shrimp Acetes Intermedius in the Coastal Waters of Southwestern Taiwan," Fish. Sci., Vol. 66, pp. 1014-1025 (2000).

5. Chou, S.C., Lee, M.A., and Lee, K.T., "Diel Vertical Movement of the Deep Scattering Layer on the Conti- 
nental Slope of I-Lan Bay, Taiwan," Fish. Sci., Vol. 65, pp. 694-699 (1999).

6. Douglas, A.S., Introduction to Ocean Science, Wadsworth, Belmont, Canada (1997).

7. Fan, K.L., "A Study of Water Masses in Taiwan Strait," Acta Oceanogr. Taiwanica, Vol. 13, pp. 140-153 (1982).

8. Hung, T.C., Tsai, C.H., and Chen, N.C., "Chemical and Biomass Studies (1) Evidence of Upwelling off the Southwestern Coast of Taiwan," Acta Oceanogr. Taiwanica, Vol. 17, pp. 29-44 (1986).

9. Kawasaki, T. and Omori, M., "Fluctuations in the Three Major Sardine Stocks in the Pacific and the Global Trend in Temperature," Proc. of the International Symposium on Long-Term Changes in Marine Fish Populations. Vigo, Spain, pp. 37-53 (1986).

10. Lalli, C.M. and Parsons, T.R., Biological Oceanography - An Introduction, Pergamon Press, Vancouver, Canada (1993).

11. Lee, D.A., Wu, I.C., Liao, I.C., and Yu, H.P., "On Three Species of Commercially Important Sergestid Shrimps (Decapoda: Sergestidae) in the Coastal Waters of Taiwan," J. Taiwan Fish. Res. Vol. 4, pp. 1-19 (1996).

12. Lee, M.A., "Fundamental Studies on the Hydroacoustic Anchovy in the Coastal Waters of Fang-Liao," Ph.D. Dissertation, Department of Fisheries Science, National Taiwan Ocean University, Keelung, Taiwan (1991). (in Chinese)

13. Lee, M.A., Lee, K.T., and Ou, H.C., "The Larval Anchovy Fishing Ground Formation in Relation to Osmotic Pressure Changes of the Coastal Waters Along Southern Taiwan," J. Fish. Soc. Taiwan, Vol. 17, pp. 233-245 (1990).
14. Lee, M.A., Lee, K.T., and Shiah, G.Y., "Seasonal Changes in Commercial Catches of Larval Anchovy in the Southwest Coastal Waters of Taiwan," J. Fish. Soc. Taiwan, Vol. 21, pp. 49-56 (1994).

15. Misistry of Eronomic Affairs, Annual Report of the Water Resources Agency, Taiwan, R.O. C. (1991-1999)

16. Omori, M., "The Biology of a Sergestid Shrimp Sergia Lucens Hansen,” Bull. Ocean Res. Inst., Vol. 4, pp. 1-83 (1969).

17. Omori, M., "Fishery of Sergestid Shrimp Sergia Lucens (Hansen) at Tung-Kang, Taiwan," J. Fish. Ocean. Soc., Vol. 53, pp. 108-110 (1989).

18. Omori, M., Ukishima, Y., and Muranaka, F., "New Record of Occurrence of Sergia Lucens (Hansen) (Crustacean, Sergestidae) off Tung-Kang, Taiwan, with Special Reference to Phylogeny and Distribution of the Species," J. Ocean. Soc., Vol. 44, pp. 261-267 (1988).

19. Rothchild, B.J. and Dsborn, T.R., "Small Scale Turbulence and Planktonic Contact Rates," J. Plankton Res., Vol. 10, pp. 465-474 (1988).

20. Siegel, H., Gerth, M., and Neumann, T., "Case Studies on Phytoplankton Blooms in Coastal and Open Waters of the Baltic Sea Using Coastal Zone Color Scanner Data," Int. J. Remote Sensing, Vol. 20, pp. 1249-1264 (1999).

21. Uda, M., Fisheries Oceanography, Koseisha Koseikaku, Tokyo, Japan (1972). (in Japanese)

22. Wang, J., "Observation of Abyssal Flows in the Northern South China Sea," Acta Oceanogr. Taiwanica, Vol. 16, pp. 36-45 (1986).

23. Wang, J. and Chern, C.S., "On Cold Water Intrusions in the Eastern Taiwan Strait During the Cold Season," Acta Oceanogr. Taiwanica, Vol. 22, pp. 43-67 (1989). 